\title{
Potential synergistic effects of sorafenib and CP-31398 for treating anaplastic thyroid cancer with p53 mutations
}

\author{
JIIN-TORNG WU ${ }^{1 *}$, CHING-LING LIN ${ }^{2,3 *}$, CHI-JUNG HUANG ${ }^{4-6}$, YU-CHE CHENG ${ }^{4,6,7}$, \\ CHIH-CHENG CHIEN ${ }^{6,8}$ and YUNG-CHUAN SUNG ${ }^{6,9}$
}

\begin{abstract}
Divisions of ${ }^{1}$ Respiratory Therapy and Chest Medicine, and ${ }^{2}$ Endocrinology and Metabolism, Department of Internal Medicine, Cathay General Hospital; ${ }^{3}$ Department of Internal Medicine, School of Medicine, College of Medicine, Taipei Medical University, Taipei 11031; ${ }^{4}$ Department of Medical Research, Cathay General Hospital; ${ }^{5}$ Department of Biochemistry, National Defense Medical Center, Taipei 11490; ${ }^{6}$ School of Medicine, College of Medicine, Fu Jen Catholic University, New Taipei 24205; ${ }^{7}$ Institute of Biomedical Engineering, Center for Biocellular Engineering, National Central University, Taoyuan 32001; ${ }^{8}$ Department of Anesthesiology, Cathay General Hospital; ${ }^{9}$ Division of Hematology/Oncology, Department of Internal Medicine, Cathay General Hospital, Taipei 10630, Taiwan, R.O.C.
\end{abstract}

Received July 10, 2019; Accepted December 19, 2019

DOI: $10.3892 / 01.2020 .11377$

\begin{abstract}
Thyroid cancer is the most commonly diagnosed endocrine cancer. Anaplastic thyroid cancer (ATC) is the most aggressive type of thyroid cancer and has a poor prognosis. Loss of p53 function has been reported to lead to poorly differentiated thyroid tumors; therefore, mutant p53 protein can be considered a crucial therapeutic target in patients with ATC. Sorafenib, a multi-kinase inhibitor, has been approved for the treatment of metastatic and differentiated thyroid cancer. Combined targeted therapy, including sorafenib, may be clinically significant for patients with ATC harboring $p 53$ mutations. In the present study, CP-31398, a p53-restoring agent, was used to improve the therapeutic efficacy of sorafenib in SW579 cells, an ATC cell line harboring $p 53$ mutations. The molecular function of CP-31398 was evaluated using western blot analysis and a luciferase reporter assay. The decreased viability of SW579 cells, following CP-31398 treatment, was augmented by sorafenib, and CP-31398 enhanced the antimitogenic effect of sorafenib; thus, sorafenib and CP-31398 synergistically inhibited the growth of SW579 cells. These results indicate
\end{abstract}

Correspondence to: Dr Yung-Chuan Sung, Division of Hematology/Oncology, Department of Internal Medicine, Cathay General Hospital, Sec. 4, 280 Renai Road, Taipei 10630, Taiwan, R.O.C.

E-mail: yungchuans@cgh.org.tw

*Contributed equally

Abbreviations: ATC, anaplastic thyroid cancer; TKIs, tyrosine kinase inhibitors

Key words: ATC, p53 mutation, sorafenib, CP-31398, combined targeted therapy a potential clinical application of CP-31398 for patients with ATC harboring p53 abnormalities, since these individuals generally respond poorly to sorafenib alone.

\section{Introduction}

Thyroid cancer is the most commonly diagnosed endocrine cancer with $\sim 60,000$ new cases diagnosed in the USA in $2018(1,2)$. Thyroid cancer is not restricted to a certain age group; however, its aggressiveness increases significantly with the age of the patient (2). Anaplastic thyroid cancer (ATC) is the most aggressive type of thyroid cancer. The incidence rate of ATC has increased between 1973 and 2014, and is still associated with a higher risk of tumor progression and cancer metastasis (3).

Normal $p 53$ acts as a tumor suppressor gene that contributes to the prevention of tumor growth (4). However, mutant p53 proteins may acquire oncogenic properties that promote tumor invasion, metastasis, cancer cell proliferation and survival (5). Point mutations in $p 53$ are frequently detected in 50-80\% of ATC tissues (6). Loss of p53 function has been reported to result in poorly differentiated thyroid tumors (6). Hence, mutant p53 protein can be considered a crucial therapeutic target in patients with ATC (6-8).

Several tyrosine kinase inhibitors (TKIs) have been used to treat advanced thyroid cancer, due to their ability to block kinases or kinase receptors $(9,10)$. TKIs can either repress cell proliferation or attenuate the neoplastic transformation of thyroid cells (11). For example, sorafenib, a multi-kinase inhibitor that acts predominantly through the inhibition of Raf-kinase and vascular endothelial growth factor receptor 2, has been approved for the treatment of metastatic and differentiated thyroid cancer $(12,13)$. However, although sorafenib may be effective in the treatment of advanced medullary thyroid cancer, it is not effective against ATC with a poor survival rate $(14,15)$. Combination treatments might improve outcomes in ATC (15), which emphasizes that combined 
targeted therapy may be highly effective for advanced thyroid carcinomas (16).

A large number of drug candidates, including small molecules or chemotherapeutic agents, have been identified or designed to rescue mutant $p 53$ and reactivate its antitumor capacity through various mechanisms. For example, PRIMA-1 can restore active conformation of mutant p53 and PK7088 can upregulate $p 21$ expression and apoptotic functions $(7,17)$. In the present study, CP-31398, a stabilizing agent that restores the wild-type conformation of mutated p53 protein (18), was used to improve the chemotherapeutic efficacy of sorafenib for p53-mutated ATC cells. The molecular function of CP-31398 was evaluated using western blot analysis and a luciferase reporter assay. Sorafenib and CP-31398 synergistically inhibited the viability of the SW579 ATC cell line. Furthermore, it was demonstrated that the combination of targeted therapy (with sorafenib) and CP-31398 potentially changed the characteristics of p53-mutant ATC cells.

\section{Materials and methods}

Cell cultures. SW579 cells that harbor p53 mutations were purchased from the American Type Culture Collection. The cells were cultured in Dulbecco's modified Eagle's medium (Lonza Group, Ltd.) supplemented with $10 \%$ fetal bovine serum (Greiner Bio-One International $\mathrm{GmbH}$ ) and antibiotics (100 U/ml penicillin and $100 \mu \mathrm{g} / \mathrm{ml}$ streptomycin; Lonza Group, Ltd.) at $37^{\circ} \mathrm{C}$ and $5 \% \mathrm{CO}_{2}$ in a humidified atmosphere.

Western blot analysis. SW579 cells were seeded onto a $15-\mathrm{cm}$ dish (at a density of $3.5 \times 10^{6}$ ) and treated with $0,0.3$ or $3 \mu \mathrm{M}$ CP-31398 (cat. no. PZ0115; Merck KGaA) for $24 \mathrm{~h}$ and placed at $37^{\circ} \mathrm{C}$ in a humidified incubator containing $5 \% \mathrm{CO}_{2}$. Total cell lysates were prepared using radioimmunoprecipitation assay buffer (cat. no. R0278; Merck KGaA) and protease inhibitors (cat. no. P8340; Merck KGaA) on ice for $5 \mathrm{~min}$. The protein concentration was determined using the Bio-Rad protein assay (Bio-Rad Laboratories, Inc.). Proteins $(30 \mu \mathrm{g})$ were separated on NuPAGE 4-12\% Bis-Tris Gel (Thermo Fisher Scientific, Inc.) and transferred to polyvinylidene difluoride membranes (cat. no. IPVH00010; Merck KGaA). The membranes were incubated with primary antibodies at room temperature for $30 \mathrm{~min}$ for the following proteins: p21 (1:200; cat. no. 2947; Cell Signaling Technology, Inc.), Noxa (1:100; cat. no. ab13654; Abcam), p53 (1:200; cat. no. SC-126; Santa Cruz Biotechnology, Inc.) and glyceraldehyde 3-phosphate dehydrogenase (GAPDH; 1:6,000; cat. no. AM4300; Thermo Fisher Scientific, Inc.). The membranes were subsequently incubated with secondary antibody at room temperature for $30 \mathrm{~min}$. The secondary antibodies were: Biotinylated anti-rabbit IgG (1:1,000; cat. no. BA-1000; Vector Laboratories, Inc.; Maravai LifeSciences) for p21; biotinylated anti-mouse IgG (1:1,000; cat. no. BA-2000; Vector Laboratories, Inc.; Maravai LifeSciences) for Noxa and p53; and horseradish peroxidase-conjugated anti-mouse IgG for GAPDH (1:5,000; cat. no. ab6808; Abcam). The bands were then visualized using: Vectastain ABC-AmP Chemiluminescence Detection kit (cat. no. AK-6601; Vector Laboratories, Inc.; Maravai LifeSciences) for p21, Noxa and p53; and the Western Lightning Ultra-ECL (cat. no. NEL113001EA; PerkinElmer, Inc.) for GAPDH; both according to the manufacturer's instructions. Finally, images were acquired and protein bands were quantified by densitometric analysis using an Alpha Innotech FluorChem FC2 Imager (version 3.2.2; ProteinSimple). The relative protein levels were calculated and determined by normalizing their expression to that of the GAPDH internal control.

Change in viability of SW579 cells following CP-31398 treatment. The growth of SW579 cells was evaluated using MTT assay (cat. no. M5655; Merck KGaA). Firstly, SW579 cells were cultured at $1 \times 10^{4}$ cells/well in 96-well plates for $24 \mathrm{~h}$. To calculate the half-maximal inhibitory concentration $\left(\mathrm{IC}_{50}\right)$ of CP-31398, the chemosensitivity of cells was determined following incubation for $24 \mathrm{~h}$ at $0,1,1.5,2,2.5,3,3.5$ and $4 \mu \mathrm{M}$. To evaluate the efficiency of adjuvant therapy, SW579 cells were treated with $1 \mu \mathrm{M}$ sorafenib (cat. no. 284461-73-0; ApexBio Technology) and $3 \mu \mathrm{M} \mathrm{CP}-31398$ alone or combined for $72 \mathrm{~h}$ and cell viability was calculated using MTT assay. The cells were then treated with $10 \mu \mathrm{l}$ of the MTT reagent, and incubated in the dark for $4 \mathrm{~h}$. Dimethyl sulfoxide (100 $\mu \mathrm{l})$ was subsequently added to dissolve the purple precipitate formed by the viable cells. The absorbance of each well at $540 \mathrm{~nm}$ was read by a Synergy HT Multi-Mode microplate reader (BioTek Instruments, Inc.). Data were obtained from three independent experiments.

Cell cycle analysis through image cytometry. The cell cycle analysis of SW579 cells was performed using a fluorescence image cytometer (NucleoCounter NC-3000; ChemoMetec A/S). SW579 cells were seeded in a 10-cm dish at a density of $1.1 \times 10^{6}$ cells per dish. Treatment with CP-31398, at concentrations of $0,0.3$ or $3 \mu \mathrm{M}$, was initiated $16 \mathrm{~h}$ following seeding. After a 72-h incubation, cells were harvested by trypsinization, loaded into a Via-1-Casette (ChemoMetec), and counted according to the manufacturer's instructions. Approximately $1.5 \times 10^{6}$ cells were suspended in $0.5 \mathrm{ml}$ of phosphate-buffered saline (PBS), and fixed with $4.5 \mathrm{ml}$ of $70 \%$ cold ethanol for at least $2 \mathrm{~h}$. Subsequently, ethanol was removed, and the cells were resuspended in PBS. Cell pellets were harvested by centrifugation at $500 \mathrm{x}$ g for $5 \mathrm{~min}$ at $4^{\circ} \mathrm{C}$ and incubated with $0.5 \mathrm{ml}$ DAPI solution [0.1\% Triton $\mathrm{X}-100$ and 4',6-diamidino-2-phenylindole (DAPI)] for $5 \mathrm{~min}$ at $37^{\circ} \mathrm{C}$. The stained cells were loaded into an NC-Slide A8 (ChemoMetec) and evaluated using a Fixed Cell Cycle-DAPI/DNA fragmentation assay protocol in the NucleoCounter NC-3000 image cytometer (ChemoMetec) (19). The acquired DNA content histograms were used to distinguish cells at different stages of the cell cycle with the NucleoView NC-3000 software (version 2.1.25.12; ChemoMetec).

Luciferase reporter assay. The p53-dependent reporter plasmid, PG13-luc, which carries the firefly luciferase gene driven by a promoter containing 13 p53-binding elements, was provided by Dr Shih-Ming Huang (Department and Graduate Institute of Biochemistry, National Defense Medical Center, Taiwan). Clones of SW579 cells expressing luciferase were obtained after transfecting the cells with PG13-luc, using the T-Pro NTRIII transfection reagent (Jifeng Biotechnology) for $5 \mathrm{~h}$ according to the manufacturer's protocol. The background levels of relative luciferase 


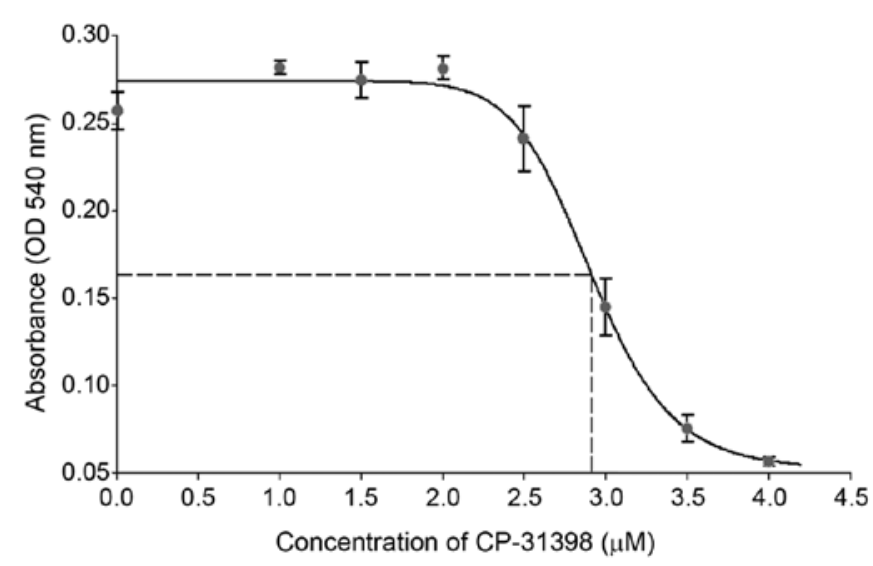

Figure 1. Potential inhibitory effect of CP-31398 on anaplastic thyroid cancer cells. SW579 cells were treated with CP-31398 $(0-4.0 \mu \mathrm{M})$ for $24 \mathrm{~h}$. MTT reagent $(10 \mu \mathrm{l})$ was administered to each well, and absorbance measurements were performed at $540 \mathrm{~nm}$. Data are presented in triplicate per drug concentration. The dash lines indicate the $\mathrm{IC}_{50}$ value $(\sim 3 \mu \mathrm{M})$.

units (RLUs) were detected from SW579 cells without PG13-luc plasmid. Luciferase activity was measured $24 \mathrm{~h}$ after the cells were treated with or without CP-31398 $(3 \mu \mathrm{M})$. The SW579/PG13-luc cell lysate (5 $\mu \mathrm{g}$ in $20 \mu \mathrm{l})$ was added to $100 \mu 1$ of the luciferase assay reagent (Luciferase Assay System with Reporter Lysis Buffer; Promega Corporation) in white clear-bottomed 96-well plates (Greiner Bio-One International $\mathrm{GmbH}$ ), in duplicate or triplicate for each experimental condition. Bioluminescence produced for $10 \mathrm{sec}$ was automatically measured under the Centro LB 960 Microplate Luminometer (Berthold Technologies GmbH).

Statistical analysis. Statistical analysis was performed using the SPSS software (version 13.0; SPSS Inc.). Numerical data are expressed as mean \pm standard deviation. The Student's t-test was used for the analysis of two groups, and one-way analysis of variance with least significant difference for multiple comparisons was performed for determining the significance of differences between the various experimental groups. $\mathrm{P}<0.05$ was considered to indicate a statistically significant difference.

\section{Results}

Determination of the $I_{50}$ of CP-31398 in p53-mutated ATC cells. CP-31398 inhibited the growth of SW579 thyroid cancer cells, an ATC cell line harboring p53 mutations $(20,21)$. The $\mathrm{IC}_{50}$ of CP-31398 in SW579 cells was determined $24 \mathrm{~h}$ after treatment with doses ranging from $0-4 \mu \mathrm{M}$. The potential inhibitory effect of CP-31398 on SW579 cells is shown in Fig. 1. The concentration of $3 \mu \mathrm{M}$ was chosen for the following experiments since it was closed to the $\mathrm{IC}_{50}(\sim 2.9 \mu \mathrm{M})$. Recent studies reported that CP-31398 restores the function of $p 53$ and could be considered as a therapeutic strategy for $p 53$-dysfunctional cancers, including cervical cancer or esophageal cancer $(22,23)$. The present study demonstrated that CP-31398 restored the function of mutated $p 53$ in SW579 cells. Firstly, $3 \mu \mathrm{M}$ CP-31398 induced the promoter activity of the plasmid PG13-luc that requires wild-type $p 53$ binding sites. As shown in Fig. 2,

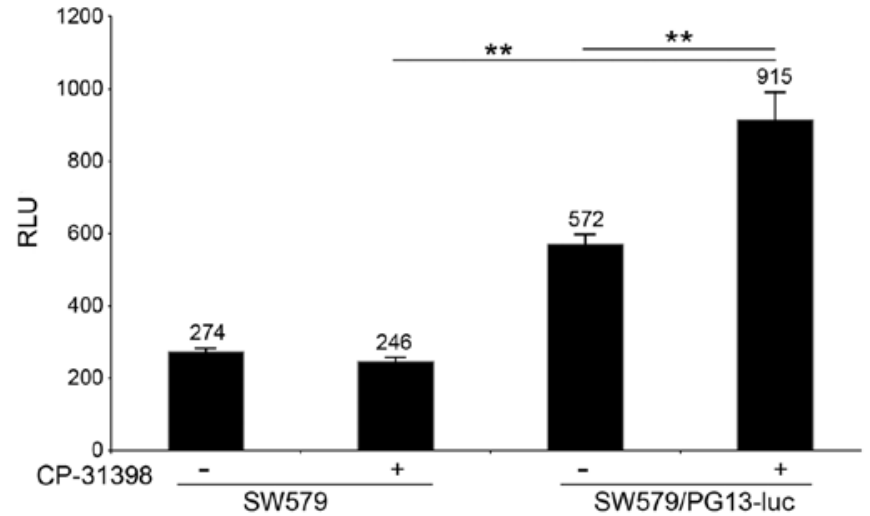

Figure 2. Restoration of p53 activity in SW579 cells by CP-31398. SW579 cells were transfected with the pPG13-luc and/or treated with CP31398, as indicated. The luciferase activity was measured $24 \mathrm{~h}$ after transfection. Data (means \pm standard deviation) are presented as RLUs of triplicate wells and indicated on top of the bars. The data were analyzed using one-way analysis of variance followed by least significant difference post hoc test. ${ }^{* *} \mathrm{P}<0.01$. +, cells with CP-31398 treatment; -, cells without CP-31398 treatment; RLUs, relative luciferase units.
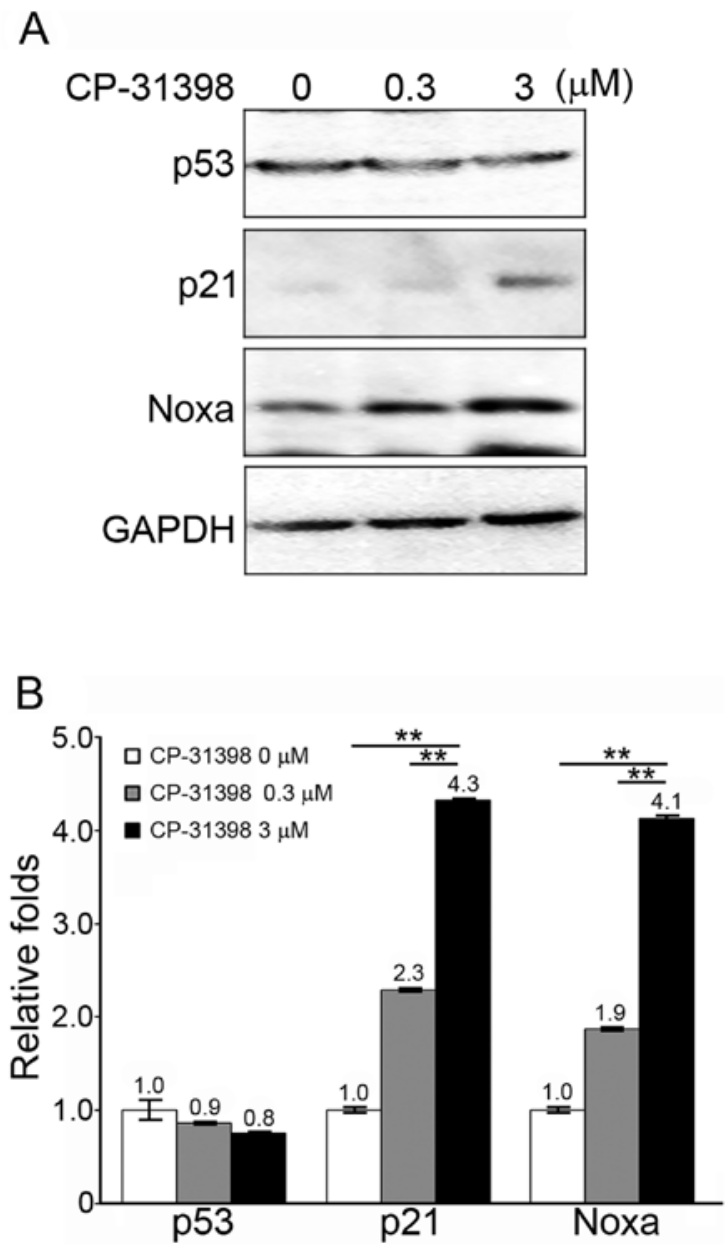

Figure 3. Western blot analyses of SW579 cells treated with CP-31398. SW579 cells were incubated with $0,0.3$ or $3 \mu \mathrm{M} \mathrm{CP}-31398$ for $24 \mathrm{~h}$. (A) Protein levels of p53, p21 and Noxa. (B) Relative quantification of p53, p21 and Noxa from western blotting. Aliquots of $30 \mu \mathrm{g}$ of lysate were separated by NuPAGE Bis-Tris gels and transferred to membranes. Images were acquired and quantified using an Alpha Innotech FluorChem FC2 Imager. GAPDH was used as endogenous control. Results were representative of one of 2-to-3 independent experiments with similar results. Data were expressed as the means \pm standard deviation. Student's t-test was used. ${ }^{* *} \mathrm{P}<0.01$. 

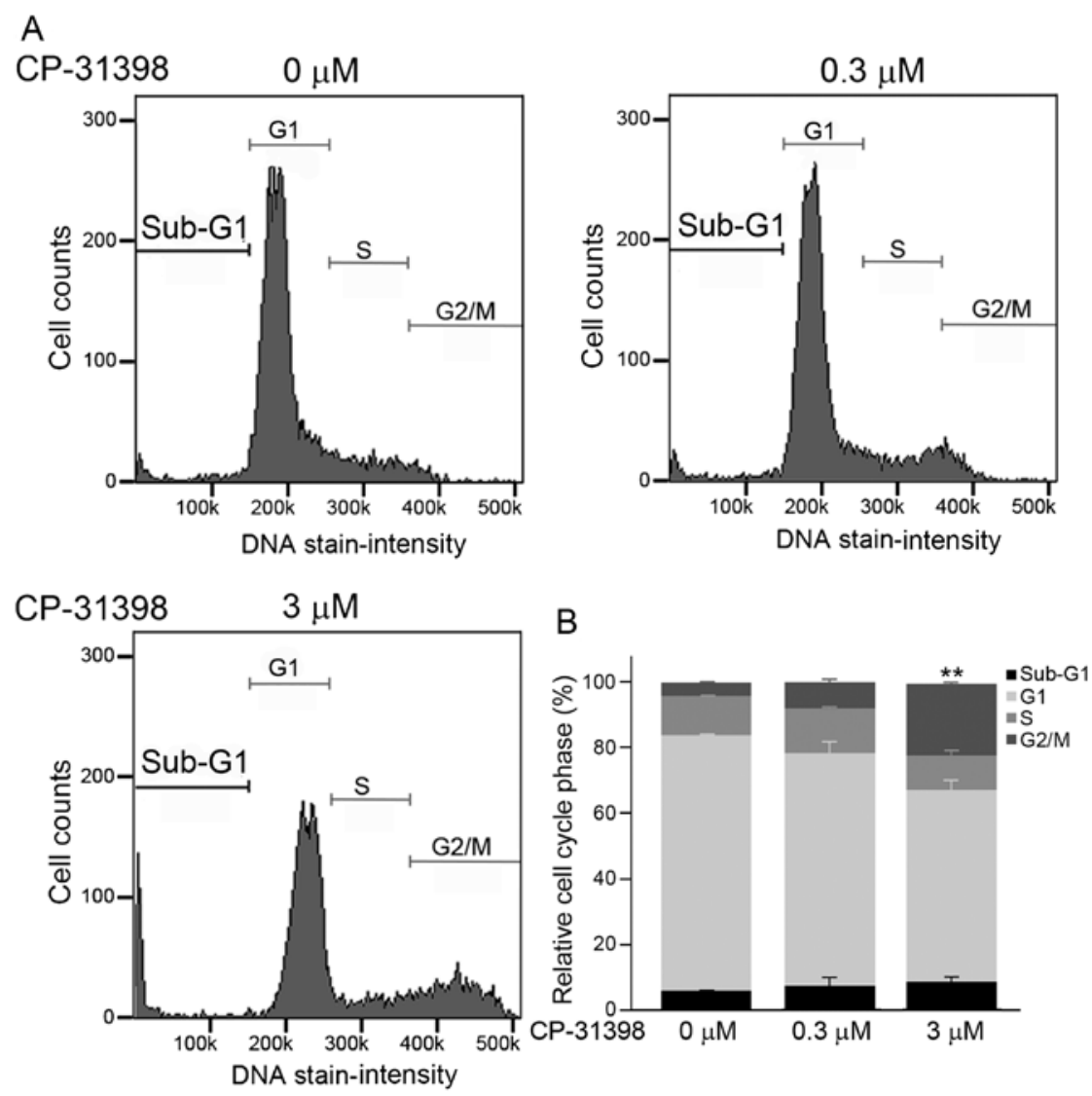

Figure 4. Effects of CP-31398 on the number of SW579 cells in the cell cycle. (A) Cell cycle distribution. (B) Statistical analysis of cell cycle phases. SW579 cells were incubated with $0,0.3$ or $3 \mu \mathrm{M}$ CP-31398 for $72 \mathrm{~h}$. The CP-31398-treated cells were loaded into a Via-1-Casette and analyzed for DAPI dyes, using a fluorescence image cytometer (NucleoCounter NC-3000). Data were expressed as the means \pm standard deviation. Student's t-test was used. ${ }^{* *} \mathrm{P}<0.01$.

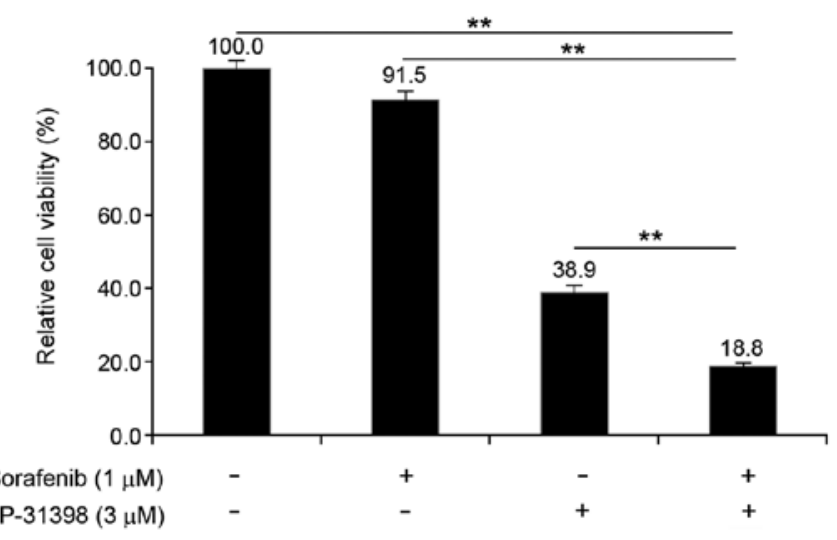

Figure 5. Suppression of SW579 cell viability by sorafenib and CP-31398 combination treatment. SW579 cells were treated with $1 \mu \mathrm{M}$ sorafenib and $3 \mu \mathrm{M} \mathrm{CP}-31398$ alone or combined for $72 \mathrm{~h}$. The viability of SW579 cells (\%, relative to cells with no drug treatment) was evaluated using the MTT assay. Data (mean \pm standard deviation) from 4-6 independent repeats are presented. The data was analyzed using one-way analysis of variance, followed by least significant difference post hoc test. ${ }^{* *} \mathrm{P}<0.01$. +, cells with sorafenib or CP-31398 treatment; -, cells without sorafenib or CP-31398 treatment.

CP-31398 significantly increased the luciferase activity from $572 \pm 26$ RLUs in non-treated cells to $915 \pm 76$ RLUs in treated SW579/PG13-luc cells $(\mathrm{P}<0.01)$. Secondly, SW579 cells treated with CP-31398 (3 $\mu \mathrm{M})$ exhibited significantly increased protein levels of p21 and Noxa, which are p53-dependent proteins (Fig. 3A and B).
CP-31398 induces apoptosis and G2/M cell cycle arrest in SW579 cells. To determine whether the increased expression of p21 and Noxa in SW579 cells, following treatment with CP-31398, matched with the induction of apoptosis, the percentages of cells at each stage of the cell cycle were determined. The cell cycle distribution in SW579 cells was examined after treatment with CP-31398 at $0,0.3$ or $3 \mu \mathrm{M}$ for $72 \mathrm{~h}$. Treatment with $3 \mu \mathrm{M}$ CP-31398 resulted in changes in cell cycle phases (Fig. 4A). Results from Fig. 4B demonstrated an increased percentage of cells with sub-G1 DNA content ( 0 to $0.3 \mu \mathrm{M},+1.5 \%$; 0.3 to $3 \mu \mathrm{M},+1.0 \%$ ), a decreased percentage of cells at $\mathrm{G} 1$ phase $(0$ to $0.3 \mu \mathrm{M},-7.5 \%$; 0.3 to $3 \mu \mathrm{M},-12.5 \%$ ), and arrested cell cycle at the $\mathrm{G} 2 / \mathrm{M}$ phase with statistical significance (0 to $3 \mu \mathrm{M},+3.5 \% ; 0.3$ to $3 \mu \mathrm{M}$, $+13.5 \%$; $\mathrm{P}<0.01$ ).

Adjuvant therapy with sorafenib for thyroid cancer in the presence of CP-31398. Sorafenib has been used to treat different types of thyroid cancer $(14,24)$. However, previous studies indicated that sorafenib has an $\mathrm{IC}_{50}$ value of $1.7 \pm 0.2 \mu \mathrm{M}$ against SW579 cells (25). In the present study, $1 \mu \mathrm{M}$ sorafenib did not effectively inhibit the viability of SW579 cells, however treatment with $3 \mu \mathrm{M}$ CP-31398 inhibited their viability after $72 \mathrm{~h}$ incubation (Fig. 5). Notably, combination treatment with $1 \mu \mathrm{M}$ sorafenib and $3 \mu \mathrm{M} \mathrm{CP}-31398$ for $72 \mathrm{~h}$ resulted in a significantly greater decrease in cell viability $(18.8 \pm 0.9$ of untreated control cells; $\mathrm{P}<0.01)$ compared with single-agent treatments $(1 \mu \mathrm{M}$ sorafenib, 91.5 $\pm 2.4 ; 3 \mu \mathrm{M} \mathrm{CP}-31398,38.9 \pm 1.8$; both $\mathrm{P}<0.01)$. 


\section{Discussion}

Although rare, ATC is one of the most aggressive human malignancies, and most patients with ATC have a poor prognosis, with a rate of thyroid cancer-associated associated-mortality of almost $50 \%$ (26). In addition, Liu et al also reported that the 2-year overall survival rate of patients with ATC was low (26.0\%) in Asia (27). In clinical settings, sorafenib provides sufficient tumor reduction to allow for thyroidectomy and radioactive iodine therapy in most types of thyroid cancer $(12,28)$. However, Ito et al (14) reported that sorafenib appeared to be effective in the treatment of advanced medullary thyroid carcinoma but not ATC. Therefore, targeted therapy with sorafenib in combination with other drugs could be clinically effective for patients with ATC (15).

In the present study, SW579 cells (carrying p53 mutations) were treated with a small-molecule agent CP-31398, which induces the desired phenotypic change (apoptosis and proliferation inhibition) in cancer cells with $p 53$ mutations $(29,30)$. CP-31398 caused notably decreased viability of SW579 cells (31). Mutated p53 (mutations at codons 151, 152, 248 and 255) is frequently detected in endocrine tumors, including ATC (21), and the DNA-binding domain of $p 53$ in SW579 cells was defective due to a point mutation at codon 255 (Ile to Ser) (31). In general, the DNA-binding ability and molecular function of p53 in SW579 cells improved when they were treated with CP-31398 (31). Xu et al (32) reported that CP-31398 treatment stabilizes the levels of mutant $p 53$ and enhances p21 protein level in rhabdomyosarcoma. In the present study, the plasmid, PG13-luc, containing a p53-binding site in its promoter was reactivated following treatment with CP-31398 in SW579 cells. Secondly the protein expression levels of two p53-dependent proteins, p21 and Noxa, were increased. However, the level of mutant p53 did not increase in the CP-31938-treated SW579 cells. These data demonstrated that the molecular function of p53 was restored when SW579 cells were treated with the optimal concentration $(3 \mu \mathrm{M})$ of CP-31398. It was hypothesized that the increased levels of $\mathrm{p} 21$ and Noxa contributed to the reduction in cell viability, by causing cells to arrest at the G2/M phase and inducing apoptosis $(33,34)$.

Furthermore, the present study demonstrated the reduction in the viability of SW579 cells by CP-31398 treatment to be augmented by the addition of the targeted therapeutic agent sorafenib. Nevertheless, the antitumor activity of combined targeted therapy with sorafenib and CP-31398 must be further investigated using an in vivo xenograft model or a real-time image of orthotopic model $(35,36)$.

In summary, the present study demonstrated that CP-31398 induces apoptosis and arrests the cell cycle at the G2/M phase in SW579 cells, by restoring the molecular function of p53. Notably, CP-31398 increased the antimitogenic effect of sorafenib, and the combination of these two agents synergistically reduced the viability of SW579 cells. Overall, the present study indicates a potential clinical application of CP-31398 for treating patients with ATC harboring p53 mutations, who generally respond poorly to sorafenib-only treatment.

\section{Acknowledgements}

The authors would like to thank Dr Shih-Ming Huang (Department of Biochemistry, National Defense Medical Center, Taipei, Taiwan R.O.C) for providing the plasmid.

\section{Funding}

The present study was supported by the Cathay General Hospital (Taipei, Taiwan; grant. no. CGH-MR-A10809; awarded to YS).

\section{Availability of data and materials}

The datasets used and/or analyzed during the current study are available from the corresponding author on reasonable request.

\section{Authors' contributions}

CLL, JTW and YCS designed the study. CLL, JTW and CJH wrote the initial version of the manuscript. CJH and CCC conducted the cell studies. CCC performed the statistical analyses. YCC performed western blotting. All authors discussed, modified and approved the final version of the manuscript.

\section{Ethics approval and consent to participate}

Not applicable.

\section{Patient consent for publication}

Not applicable.

\section{Competing interests}

The authors declare that they have no competing interests.

\section{References}

1. Siegel RL, Miller KD and Jemal A: Cancer statistics, 2018. CA Cancer J Clin 68: 7-30, 2018.

2. Blackburn BE, Ganz PA, Rowe K, Snyder J, Wan Y, Deshmukh V, Newman M, Fraser A, Smith K, Herget K, et al: Aging-related disease risks among young thyroid cancer survivors. Cancer Epidemiol Biomarkers Prev 26: 1695-1704, 2017.

3. Janz TA, Neskey DM, Nguyen SA and Lentsch EJ: Is the incidence of anaplastic thyroid cancer increasing: A population based epidemiology study. World J Otorhinolaryngol Head Neck Surg 5: 34-40, 2018

4. Labuschagne $\mathrm{CF}$, Zani $\mathrm{F}$ and Vousden $\mathrm{KH}$ : Control of metabolism by p53-cancer and beyond. Biochim Biophys Acta Rev Cancer 1870: 32-42, 2018.

5. Muller PA and Vousden KH: p53 mutations in cancer. Nat Cell Biol 15: 2-8, 2013.

6. Manzella L, Stella S, Pennisi MS, Tirro E, Massimino M, Romano C, Puma A, Tavarelli M and Vigneri P: New insights in thyroid cancer and p53 family proteins. Int J Mol Sci 18: E1325, 2017.

7. Li Y, Wang Z, Chen Y, Petersen RB, Zheng L and Huang K: Salvation of the fallen angel: Reactivating mutant p53. Br J Pharmacol 176: 817-831, 2019.

8. Liu L, Li D, Chen Z, Yang J, Ma Y, Cai H, Shan C, Lv Z and Zhang X: Wild-type p53 induces sodium/iodide symporter expression allowing radioiodide therapy in anaplastic thyroid cancer. Cell Physiol Biochem 43: 905-914, 2017.

9. Date E, Okamoto K, Fumita S and Kaneda H: Gastrointestinal perforation related to lenvatinib, an anti-angiogenic inhibitor that targets multiple receptor tyrosine kinases, in a patient with metastatic thyroid cancer. Invest New Drugs 36: 350-353, 2018.

10. Saito Y, Sugino K, Takami H, Matsuzu K, Uruno T, Ohkuwa K, Kitagawa W, Nagahama M, Kawakubo H, Ito K and Kitagawa Y: Clinical status and treatment of liver metastasis of differentiated thyroid cancer using tyrosine kinase inhibitors. World J Surg 42: 3632-3637, 2018.

11. Cabanillas ME, McFadden DG and Durante C: Thyroid cancer. Lancet 388: 2783-2795, 2016. 
12. Corrado A, Ferrari SM, Politti U, Mazzi V, Miccoli M, Materazzi G, Antonelli A, Ulisse S, Fallahi P and Miccoli P: Aggressive thyroid cancer: Targeted therapy with sorafenib. Minerva Endocrinol 42: 64-76, 2017.

13. Ramakrishnan V, Timm M, Haug JL, Kimlinger TK, Wellik LE, Witzig TE, Rajkumar SV, Adjei AA and Kumar S: Sorafenib, a dual Raf kinase/vascular endothelial growth factor receptor inhibitor has significant anti-myeloma activity and synergizes with common anti-myeloma drugs. Oncogene 29: 1190-1202, 2010.

14. Ito Y, Onoda N, Ito KI, Sugitani I, Takahashi S, Yamaguchi I, Kabu K and Tsukada K: Sorafenib in Japanese patients with locally advanced or metastatic medullary thyroid carcinoma and anaplastic thyroid carcinoma. Thyroid 27: 1142-1148, 2017.

15. Chen G, Nicula D, Renko K and Derwahl M: Synergistic anti-proliferative effect of metformin and sorafenib on growth of anaplastic thyroid cancer cells and their stem cells. Oncol Rep 33: 1994-2000, 2015.

16. Orlandi F, Caraci P, Berruti A, Puligheddu B, Pivano G, Dogliotti L and Angeli A: Chemotherapy with dacarbazine and 5-fluorouracil in advanced medullary thyroid cancer. Ann Oncol 5: 763-765, 1994.

17. Binayke A, Mishra S, Suman P, Das S and Chander H: Awakening the 'guardian of genome': Reactivation of mutant p53. Cancer Chemother Pharmacol 83: 1-15, 2019.

18. Mularski J, Malarz K, Pacholczyk M and Musiol R: The p53 stabilizing agent CP-31398 and multi-kinase inhibitors. Designing, synthesizing and screening of styrylquinazoline series. Eur J Med Chem 163: 610-625, 2019.

19. Beberok A, Rzepka Z, Respondek M, Rok J, Stradowski M and Wrześniok D: Moxifloxacin as an inducer of apoptosis in melanoma cells: A study at the cellular and molecular level. Toxicol In Vitro 55: 75-92, 2019.

20. Huang LC, Tam KW, Liu WN, Lin CY, Hsu KW, Hsieh WS, Chi WM, Lee AW, Yang JM, Lin CL and Lee CH: CRISPR/Cas9 genome editing of epidermal growth factor receptor sufficiently abolished oncogenicity in anaplastic thyroid cancer. Dis Markers 2018: 3835783, 2018.

21. Yoshimoto K, Iwahana H, Fukuda A, Sano T, Saito S and Itakura M: Role of p53 mutations in endocrine tumorigenesis: Mutation detection by polymerase chain reaction-single strand conformation polymorphism. Cancer Res 52: 5061-5064, 1992.

22. Liu L, Yu TT, Ren CC, Yang L, Cui SH and Zhang XA: CP-31398 inhibits the progression of cervical cancer through reversing the epithelial mesenchymal transition via the downregulation of PAX2s. J Cell Physiol 234: 2929-2942, 2019.

23. Zhong B, Shingyoji M, Hanazono M, Nguyen TTT, Morinaga T, Tada Y, Hiroshima K, Shimada H and Tagawa M: A p53-stabilizing agent, CP-31398, induces p21 expression with increased G2/M phase through the YY1 transcription factor in esophageal carcinoma defective of the p53 pathway. Am J Cancer Res 9: 79-93, 2019.

24. Krajewska J, Handkiewicz-Junak D and Jarzab B: Sorafenib for the treatment of thyroid cancer: An updated review. Expert Opin Pharmacother 16: 573-583, 2015.
25. Wang L, Zhang Y, Zhang Q, Zhu G, Zhang Z, Duan C, Lu T and Tang W: Discovery of potent Pan-Raf inhibitors with increased solubility to overcome drug resistance. Eur J Med Chem 163: 243-255, 2019.

26. Salehian B, Liem SY, Mojazi Amiri H and Maghami E: Clinical trials in management of anaplastic thyroid carcinoma; progressions and set backs: A systematic review. Int J Endocrinol Metab 17: e67759, 2019.

27. Liu TR, Xiao ZW, Xu HN, Long Z, Wei FQ, Zhuang SM, Sun XM, Xie LE, Mu JS, Yang AK, et al: Treatment and prognosis of anaplastic thyroid carcinoma: A clinical study of 50 cases. PLoS One 11: e0164840, 2016.

28. Danilovic DLS, Castro G Jr, Roitberg FSR, Vanderlei FAB, Bonani FA, Freitas RMC, Coura-Filho GB, Camargo RY, Kulcsar MA, Marui S and Hoff AO: Potential role of sorafenib as neoadjuvant therapy in unresectable papillary thyroid cancer. Arch Endocrinol Metab 62: 370-375, 2018.

29. Arihara Y, Takada K, Kamihara Y, Hayasaka N, Nakamura H, Murase K, Ikeda H, Iyama S, Sato T, Miyanishi K, et al: Small molecule CP-31398 induces reactive oxygen species-dependent apoptosis in human multiple myeloma. Oncotarget 8 : 65889-65899, 2017.

30. He XX, Zhang YN, Yan JW, Yan JJ, Wu Q and Song YH CP-31398 inhibits the growth of p53-mutated liver cancer cells in vitro and in vivo. Tumour Biol 37: 807-815, 2016.

31. Grassi ES, Vezzoli V, Negri I, Labadi A, Fugazzola L, Vitale G and Persani L: SP600125 has a remarkable anticancer potential against undifferentiated thyroid cancer through selective action on ROCK and p53 pathways. Oncotarget 6: 36383-36399, 2015.

32. Xu J, Timares L, Heilpern C, Weng Z, Li C, Xu H, Pressey JG, Elmets CA, Kopelovich L and Athar M: Targeting wild-type and mutant p53 with small molecule CP-31398 blocks the growth of rhabdomyosarcoma by inducing reactive oxygen species-dependent apoptosis. Cancer Res 70: 6566-6576, 2010.

33. Karimian A, Ahmadi Y and Yousefi B: Multiple functions of $p 21$ in cell cycle, apoptosis and transcriptional regulation after DNA damage. DNA Repair (Amst) 42: 63-71, 2016.

34. Shibue T, Takeda K, Oda E, Tanaka H, Murasawa H, Takaoka A, Morishita Y, Akira S, Taniguchi T and Tanaka N: Integral role of Noxa in p53-mediated apoptotic response. Genes Dev 17: 2233-2238, 2003.

35. Tran Cao HS, Kaushal S, Snyder CS, Ongkeko WM, Hoffman RM and Bouvet M: Real-time imaging of tumor progression in a fluorescent orthotopic mouse model of thyroid cancer. Anticancer Res 30: 4415-4422, 2010

36. Kim S, Yazici YD, Calzada G, Wang ZY, Younes MN, Jasser SA, El-Naggar AK and Myers JN: Sorafenib inhibits the angiogenesis and growth of orthotopic anaplastic thyroid carcinoma xenografts in nude mice. Mol Cancer Ther 6: 1785-1792, 2007. 